\title{
Assessment of medication adherence among patients with chronic diseases: a descriptive cross-sectional study
}

\author{
Shakeel Ahmad Mir ${ }^{1 *}$, Furqanah Muzamil'2, Mehraj UD Din Bhat ${ }^{1}$, \\ Abid Amin ${ }^{3}$, Danish Shakeel ${ }^{4}$
}

${ }^{1}$ Department of Clinical Pharmacology, Sher-I-Kashmir Institute of Medical Sciences (SKIMS), Srinagar, Kashmir, India

${ }^{2}$ MBBS Student, SKIMS

Medical College Bemina, Sher-

I-Kashmir Institute of Medical

Sciences (SKIMS), Srinagar,

Kashmir, India

${ }^{3}$ Research Scholar, General

Medicine, Sher-I-Kashmir

Institute of Medical Sciences

(SKIMS), Srinagar, Kashmir,

India

${ }^{4}$ Student, CSE IBM, Chandigarh

University, Mohali, Punjab,

India

Received: 16 October 2018

Accepted: 19 November 2018

*Correspondence to:

Dr. Shakeel Ahmad Mir,

Email: shakeel.mir@skims.ac.in

Copyright: () the author(s), publisher and licensee Medip Academy. This is an openaccess article distributed under the terms of the Creative Commons Attribution NonCommercial License, which permits unrestricted noncommercial use, distribution, and reproduction in any medium, provided the original work is properly cited.

\begin{abstract}
Background: Adherence is a key factor associated with effectiveness of all pharmacological therapies. Medication non-adherence is a significant barrier to achieve positive health outcomes especially for patients suffering from chronic diseases. Improving medication adherence is a public health priority and could reduce economic and health burdens. The aim of the present study was to assess medication adherence to some common chronic ailments.

Methods: Pre-validated questionnaires were distributed among 300 patients suffering from chronic illnesses, by simple randomization out of which 240 patients returned completely filled questionnaires. The analysis was done by manual calculators, VassarStats, and SPSS V20. Results were calculated using univariate linear regression, with each patient's adherence score as the dependent variable and each predictor as the independent variable. Results are expressed in frequencies and percentages.

Results: In this study, $46.66 \%$ patients were males and $53.33 \%$ females. The mean age was 56.69 years ranging from 24 to 90 years. $65.00 \%$ patients were uneducated.40.00\% were taking one drug, $53.33 \%$ two to four drugs and $6.66 \%$ more than four drugs. $63.33 \%$ had low medication adherence, $35.00 \%$ medium and only $1.66 \%$ had high adherence. Compared to $14.28 \%$ men, $43.75 \%$ women were moderately adherent to medications. $41.02 \%$ uneducated patients had medium adherence as compared to $14.28 \%$ educated patients. $92.30 \%$ young patients had low adherence as compared to $53.25 \%$ in adults. $44.79 \%$ of patients receiving a single drug had medium adherence as compared to $25.00 \%$ in those receiving multiple drugs. Linear regression analysis demonstrated that the level of medication adherence was associated with patient gender, age, educational level, and number of prescribed drugs.

Conclusions: There are many challenges in understanding the reasons for nonadherence. In this study medication adherence in chronic diseases was found suboptimal and associated with patient's socio-demographic characteristics. Patient-tailored interventions are required to achieve sufficient adherence to therapeutic drug regimens.
\end{abstract}

Keywords: Adherence, Health care, Medication, Treatment

\section{INTRODUCTION}

The WHO defines adherence to long term therapy as the extent to which a person`s behavior-taking medication, following a diet and/or executing lifestyle changescorrespond with agreed recommendations from a healthcare provider. ${ }^{1}$ Adherence is a key factor for the effectiveness of all pharmacological therapies but is 
particularly critical for medications prescribed for chronic conditions. ${ }^{2}$ The treatment of chronic disease is often complicated by the coexistence of multiple medical conditions and by the presence of social and psychological impediments. ${ }^{3}$ The average rates of adherence in clinical trials can be remarkably high, owing to the attention study patients receive and to selection of the patients, yet even clinical trials report average adherence rates of only 43 to 78 percent among patients receiving treatment for chronic conditions. $^{4}$

Adherence to therapies is a primary determinant of treatment success. non-adherence is a serious problem which not only affects the patient but also the health care system. $^{5}$

Poor adherence to the treatment of chronic diseases is a worldwide problem of striking magnitude. It has been found that approximately $50 \%$ of the patients do not adhere to one of their chronic medications. Poor adherence to long term therapies severely compromises the effectiveness of treatment making this a critical issue in the population health. ${ }^{1}$ It can result in more rapid disease progression, adverse health outcomes and increased use of costly healthcare services. ${ }^{6}$

Nonadherence is found in all diseases where the selfadministration of the medication is required. Despite increased awareness poor adherence to treatment for chronic diseases remains a global problem. ${ }^{7}$

Measurement of medication adherence is challenging because adherence is an individual patient behavior. There have been many approaches to measure medication adherence such as patient reports, pharmacy documents, tests for biomarkers, and electronic monitoring devices. The Eight-item Morisky Medication Adherence Scale (MMAS-8) is one of the simplest self reporting scales measuring medication adherence behavior. ${ }^{8}$

Adherence problems have generally been overlooked and have received little attention. The aim of the present study was to investigate the medication adherence pattern in some common chronic diseases.

\section{METHODS}

A descriptive cross sectional questionnaire based study was conducted in a time span of six months from March 2018 to August 2018, among patients attending various healthcare facilities in Kashmir. Sample size calculation was done to determine the population required for the study.

\section{Sample size calculation}

$\mathrm{n}=\mathrm{pq} /(\mathrm{E} / 1.96)^{2}$ where;

- $\quad \mathrm{n}=$ minimum sample size
- $\quad \mathrm{p}=$ prevalence of medication adherence as reported in various studies in the region.

- $\quad \mathrm{q}=100-\mathrm{p}$

- $\quad \mathrm{E}=$ margin of sample error tolerated $(\%)$

- $\quad=5 \%$ i.e. $95 \%$ confidence interval

\section{Study population}

A Total of 300 patients selected by simple randomization were given a pre-validated questionnaire out of which only 248 returned it. Eight of them had answered incompletely hence data of only 240 participants were considered for the study and the rest were excluded.

Sampling was done by Simple random method.

\section{Inclusion criteria}

- Inhabitant of study area

- $\quad$ Suffering from chronic disease

- $\quad$ Ability to communicate by at least one of the means viz. speaking or writing

- Consuming medicine under doctor's prescription

- $\quad$ Age more than 18 years.

\section{Exclusion criteria}

- Inhabitant outside the study area

- Of insane mind

- Unable to communicate

- Self-medicating

- $\quad$ Age Less than 18 years.

\section{Study tools}

Pre-tested questionnaire which was prepared in English. It contained three sections. Section first included the questions regarding the general demographic information such as age, gender, location, educational qualification etc. Section two had questions about disease and medication. Section 3 asked questions about medication adherence, as per eight point Morisky Medication Adherence Scale (MMAS-8). After proper approval from institutional Ethics committee, the objectives of the study were explained to the study participants prior to data collection, and their consents were sought and the questionnaires were filled only by those who agreed. The confidentiality of the responders was maintained.

\section{Data entry, analysis and interpretation}

Analysis was done by combination of manual calculators, VassarStats and SPSS software packageV20.

\section{RESULTS}

A total of 300 patients recruited through simple random sampling participated in the survey. Data were collected by the use of well structured questionnaires. Results were 
calculated using univariate linear regression, with each patient's adherence score as the dependent variable and each predictor as the independent variable.

Results are summarized and reported using simple descriptive statistics (No. and \%ages) in Table 1 to 3.

Table 1: Characteristics of study population.

\begin{tabular}{|c|c|c|}
\hline \multicolumn{3}{|c|}{ Characteristics } \\
\hline Gender & No. & $\%$ \\
\hline Male & 112 & 46.66 \\
\hline Female & 128 & 53.33 \\
\hline \multicolumn{3}{|c|}{ Marital status } \\
\hline Married & 232 & 96.66 \\
\hline Unmarried & 08 & 3.33 \\
\hline \multicolumn{3}{|c|}{ Age group: Age (mean: 56.69) } \\
\hline $20-25$ yrs & 12 & 5.00 \\
\hline $26-30$ yrs & 12 & 5.00 \\
\hline $31-35$ yrs & 16 & 6.66 \\
\hline $36-40$ yrs & 12 & 5.00 \\
\hline $41-45$ yrs & 20 & 8.33 \\
\hline $46-50 \mathrm{yrs}$ & 08 & 3.33 \\
\hline $51-55$ yrs & 12 & 5.00 \\
\hline $56-60$ yrs & 44 & 18.33 \\
\hline $61-65$ yrs & 48 & 20.00 \\
\hline $66-70 \mathrm{yrs}$ & 16 & 6.66 \\
\hline $71-75$ yrs & 28 & 11.66 \\
\hline$>75 \mathrm{yrs}$ & 12 & 5.00 \\
\hline \multicolumn{3}{|c|}{ Educational status (Literacy) } \\
\hline Literate & 84 & 35.00 \\
\hline Illiterate & 156 & 65.00 \\
\hline \multicolumn{3}{|l|}{ Residence } \\
\hline Urban & 16 & 06.66 \\
\hline Rural & 180 & 75.00 \\
\hline City & 44 & 18.33 \\
\hline
\end{tabular}

Table 1 shows patient characteristics. These include patient age, gender, residence area, marital status, and level of education. The study population consisted of $46.66 \%$ men and $53.33 \%$ women. The mean age was 56.69 years ranging from 24 to 90 years. $35.00 \%$ patients were literate and $65.00 \%$ were illiterate. $6.66 \%$ patients were from urban areas, $75.00 \%$ from rural areas and $18.33 \%$ from Srinagar city. $96.66 \%$ patients were married.

Table 2 shows that $41.66 \%$ patients were receiving medications for Hypertension, $31.66 \%$ for COPD and asthma, $16.66 \%$ for Diabetes Mellitus, and, $10.00 \%$ for rheumatoid arthritis. $8.33 \%$ had a disease of less than oneyear duration, $58.33 \%$ one to five years, $25.00 \%$ six to ten years and $8.33 \%$ patients had a disease of more than ten years duration. $16.66 \%$ had been receiving medication for less a year, $50.00 \%$ for 1 year to 5 years, $25.00 \%$ for 6 years to 10 years, and $8.33 \%$ for more than 10 years. $40.00 \%$ were taking one drug, $53.33 \%$ two to four drugs and $6.66 \%$ more than four drugs. $43.33 \%$ were taking $\operatorname{drug}(\mathrm{s})$ once a day, $30.00 \%$ twice a day, $15.00 \%$ thrice a day and $11.66 \%$ more than three times a day. $76.66 \%$ were satisfied with the treatment they received but $23.33 \%$ expressed dissatisfaction for various reasons.

Table 2: Disease and medication pattern of study population.

\begin{tabular}{|c|c|c|}
\hline Characteristics & No. & $\%$ \\
\hline \multicolumn{3}{|l|}{ Disease type } \\
\hline Hypertension & 100 & 41.66 \\
\hline COPD/Asthma & 76 & 31.66 \\
\hline Diabetes Mellitus & 40 & 16.66 \\
\hline Rheumatoid arthritis & 24 & 10.00 \\
\hline \multicolumn{3}{|l|}{ Duration of illness } \\
\hline$<1 \mathrm{yr}$ & 20 & 08.33 \\
\hline $1-5$ yrs & 140 & 58.33 \\
\hline $6-10 \mathrm{yrs}$ & 60 & 25.00 \\
\hline$>10 \mathrm{yrs}$ & 20 & 08.33 \\
\hline \multicolumn{3}{|l|}{ Duration of treatment } \\
\hline$<1 \mathrm{yr}$ & 40 & 16.66 \\
\hline $1-5$ yrs & 120 & 50.00 \\
\hline $6-10 \mathrm{yrs}$ & 60 & 25.00 \\
\hline$>10 \mathrm{yrs}$ & 20 & 08.33 \\
\hline \multicolumn{3}{|c|}{ Number of drugs prescribed } \\
\hline One drug & 96 & 40.00 \\
\hline 2-4 Drugs & 128 & 53.33 \\
\hline$>4$ Drugs & 16 & 06.66 \\
\hline \multicolumn{3}{|c|}{ Frequency of drug administration } \\
\hline Once a day & 104 & 43.33 \\
\hline Twice a day & 72 & 30.00 \\
\hline Thrice a day & 36 & 15.00 \\
\hline$>$ Thrice a day & 28 & 11.66 \\
\hline \multicolumn{3}{|c|}{ Treatment satisfaction } \\
\hline Yes & 184 & 76.66 \\
\hline No & 56 & 23.33 \\
\hline
\end{tabular}

Table 3 shows medication adherence levels. $63.33 \%$ had low medication adherence as per 8 points Morisky Medication Adherence Scale, 35.00\% medium and only $1.66 \%$ had high adherence. Compared to $14.28 \%$ men, $43.75 \%$ women were moderately adherent to medications. $41.02 \%$ uneducated patients had medium adherence as compared to $14.28 \%$ educated patients. $92.30 \%$ young patients had low adherence and $7.69 \%$ had medium adherence. In older patients, $53.25 \%$ had low adherence, $44.68 \%$ medium and $2.12 \%$ high adherence. $44.79 \%$ patients receiving a single drug had medium adherence and $25.00 \%$ patients receiving multiple drugs had medium adherence.

\section{DISCUSSION}

Medication adherence remains a major public health concern and is expected to continue as the population ages and becomes increasingly reliant on self-administered medications. It is a critical element for chronic disease management. ${ }^{9}$ 
Medication non-adherence is a significant barrier for positive health outcomes for patients with chronic diseases. ${ }^{4}$ There is a wide variation in reported non adherence, depending upon: definitions of adherence, the population studied, methodology used, length of observation and data analysis tools used. ${ }^{10}$

Table 3: Observed adherence in study population by Morisky Medication Adherence Scale (MMAS-8).

\begin{tabular}{|c|c|c|}
\hline Level & No. & $\%$ \\
\hline \multicolumn{3}{|c|}{ Overall adherence level } \\
\hline Low & 152 & 63.33 \\
\hline Medium & 84 & 35.00 \\
\hline High & 04 & 01.66 \\
\hline \multicolumn{3}{|c|}{ Gender-wise adherence Level } \\
\hline \multicolumn{3}{|c|}{ Males (112) } \\
\hline Low & 96 & 85.71 \\
\hline Medium & 16 & 14.28 \\
\hline High & 0 & 0 \\
\hline \multicolumn{3}{|c|}{ Females (128) } \\
\hline Low & 68 & 53.12 \\
\hline Medium & 56 & 43.75 \\
\hline High & 04 & 03.12 \\
\hline \multicolumn{3}{|c|}{ Level of education and adherence Level } \\
\hline \multicolumn{3}{|c|}{ Uneducated (156) } \\
\hline Low & 92 & 58.97 \\
\hline Medium & 64 & 41.02 \\
\hline High & 0 & 0 \\
\hline \multicolumn{3}{|c|}{ Educated (84) } \\
\hline Low & 68 & 80.95 \\
\hline Medium & 12 & 14.28 \\
\hline High & 04 & 4.76 \\
\hline \multicolumn{3}{|c|}{ Age-wise adherence Level } \\
\hline \multicolumn{3}{|c|}{ Young adults (52) } \\
\hline Low & 48 & 92.30 \\
\hline Medium & 04 & 07.69 \\
\hline High & 0 & 0 \\
\hline \multicolumn{3}{|c|}{ Old adults (188) } \\
\hline Low & 100 & 53.25 \\
\hline Medium & 84 & 44.68 \\
\hline High & 04 & 02.12 \\
\hline \multicolumn{3}{|c|}{ Adherence level with Monotherapy vs polypharmac } \\
\hline \multicolumn{3}{|c|}{ Monotherapy (96) } \\
\hline Low & 53 & 55.20 \\
\hline Medium & 53 & 44.79 \\
\hline High & 0 & \\
\hline \multicolumn{3}{|c|}{ Polypharmacy (144) } \\
\hline Low & 104 & 72.22 \\
\hline Medium & 36 & 25.00 \\
\hline High & 04 & 2.77 \\
\hline
\end{tabular}

Measurement of medication adherence is challenging because adherence is an individual patient behavior. Various approaches have been used to measure medication adherence. We used Eight point Morisky Medication Adherence Scale(MMAS-8) in the study. The Morisky scale is a commonly used, validated self reporting adherence measure that has been shown to be predictive of adherence to medication. ${ }^{11}$

This study determined the level of medication adherence in some common chronic ailments. The comparison of adherence with similar studies conducted in various countries is difficult because of differences in patient characteristics and data collection tools.

It was observed that out of 240 patients aged between 24 years to 90 years $(M=56.69, S D=13.12), 63.30 \%$ had low, $35.00 \%$ medium, and only $1.66 \%$ high medication adherence.

It was also observed that female patients had better reported medication adherence $(46.87 \%$ medium and high) as compared to male patients $(14.28 \%)(\mathrm{p}=0.81)$. These results are consistent with another study in which women were found more adherent. ${ }^{12}$ but are different from other studies in which males were found more adherent. ${ }^{13,14}$

Authors have found that elderly people were more adherent to medication ( $46.80 \%$ medium and high) as compared to young patients $(7.69 \%)(\mathrm{p}=0.17)$. The results are consistent with other studies in which the prevalence of adherence was significantly lower in younger patients. ${ }^{15-18}$

In this study, uneducated patients were found more adherent (41.02\%) than educated patients (19.04\%, $\mathrm{p}=0.27$ ) In another study uneducated patients were $75.00 \%$ adherent to medication and educated patients had lower adherence rates $(71.4 \%)$. In one more study similar result were found. ${ }^{19}$

Patients receiving a single drug had better adherence (44.79\% medium) than those receiving multiple drugs (27.77\% medium and high combined) $(\mathrm{p}=0.27)$. Similar results were found in another study. ${ }^{20}$ In another study it was concluded that, there appears to be an association between polypharmacy and poorer medication adherence in older adults. ${ }^{10}$

In this study poor correlation was found between the disease duration, frequency of drug administration and medication adherence. These findings are similar to those of Mitchell et al in another study. ${ }^{19}$ By Pearson Correlation, age, gender, educational level and number of prescribed drugs were found directly or inversely related to the level of medication adherence.

The differences in reported medication adherence found in this study, though statistically insignificant, may be clinically important.

One limitation of this study is recall bias. We tried to minimize it by a using a well structured pre-validated questionnaire based on Morisky Medication Adherence Scale which is one of the simplest self reporting scales 
measuring medication adherence behavior and the reliability and validity of which has been well established. Another limitation of this study is the limited sample size, which we tried to overcome by use of a random sampling method so as to generalize findings.

\section{CONCLUSION}

Adherence is a key factor associated with the effectiveness of all pharmacological therapies but is particularly critical for medications used in chronic diseases. The reasons for poor medication adherence are often multifactorial. The present study found a relationship between gender, age, literacy, complexity of drug regimens and medication adherence. Further studies with large sample size must be done to understand all the reasons for patient medication non-adherence.

\section{ACKNOWLEDGEMENT}

The authors wish to thank Danish Shakeel, CSE IBM student of Chandigarh University, Mohali, Punjab, India for helping in tabulation and statistical analysis of data.

Funding: No funding sources

Conflict of interest: None declared

Ethical approval: The study was approved by the Institutional Ethics Committee

\section{REFERENCES}

1. Sabate E. Adherence to long-term therapies: Evidence for action. Geneva: World Health Organization; 2003. Available http://apps.who.int/medicinedocs/pdf/s4883e/s4883e. pdf

2. Brown MT, Bussell JK. Medication adherence: WHO cares? Mayo Clin Proc. 2011;86(4):304-14.

3. DeBusk RF, West JA, Miller NH, Taylor CB. Chronic disease management: treating the patient with disease(s) vs treating disease(s) in the patient. Arch Intern Med. 1999 Dec 13-27;159(22):2739-42.

4. Osterberg L, Blaschke T. Adherence to medication. N Engl J Med. 2005;353:487-97.

5. Jimmy B, Jose J. Patient medication adherence: measures in daily practice. Oman Med J. 2011;26(3):155-9.

6. Andrew WR, Ginny DC, Denise AE, Mary TR, Morris W, Joel FF. Patterns of Medication Adherence and Health Care Utilization Among Patients with Chronic Disease Who Were Enrolled in a Pharmacy Assistance Program. N C Med J. 2014;75(5):310-8.

7. Vrijens B, Antoniou S, Burnier M, de la Sierra A, Volpe M. Current Situation of Medication Adherence in Hypertension. Front. Pharmacol. 2017;8:100.

8. Morisky DE, Ang A, Krousel-Wood M, Ward HJ. Predictive validity of a medication adherence measure in an outpatient setting. J. Clin. Hypertens. 2008; 10:348-54.
9. Zullig LL, Hayden BB. Medication Adherence: A Practical Measurement Selection Guide Using Case Studies. Patient Educ Couns. 2017 July;100(7):14104.

10. Zachary AM, Walid FG. Medication Adherence to Multi-Drug Regimens. Clin Geriatr Med. 2012 May;28(2):287-300.

11. Morisky DE, Green LW, Levine DM. Concurrent and predictive validity of a self-reported measure of medication adherence. Med Care. 1986;24:67-74.

12. Rosita S, Kjell T, Karl AF, Thorarinn G, Ernst O, Cecilie S, et al. Asthma in men and women: Treatment adherence, anxiety, and quality of sleep. Respiratory Medicine. 2010;104:337e344

13. Manteuffel M, Williams S, Chen W, Verbrugge RR, Pittman DG, Steinkellner A. Influence of patient sex and gender on medication use, adherence, and prescribing alignment with guidelines. J Womens Health (Larchmt). 2014 Feb;23(2):112-9.

14. Chen SL, Lee WL, Liang T, Liao IC. Factors associated with gender differences in medication adherence: a longitudinal study.J Adv Nurs. 2014 Sep;70(9):2031-40.

15. Marya JC, Shimon S, Courtney C, Sunil K, Michael KP, Jeffrey LS. Predictors of medication adherence postdischarge: The impact of patient age, insurance status, and prior adherence. J Hosp Med. 2012 July;7(6):470-5.

16. Bandi P, Goldmann E, Parikh NS, Farsi P, BodenAlbala B. Age-related differences in antihypertensive medication adherence in Hispanics: a cross-sectional community-based survey in New York City, 20112012. Prev Chronic Dis. 2017;14:E57

17. Leven EA, Annunziato R, Helcer J, Lieber SR, Knight $\mathrm{CS}$, Wlodarkiewicz C, et al. Medication adherence and rejection rates in older vs younger adult liver transplant recipients. Clin Transplant. 2017 Jun;31(6).

18. Shrinivasa BM, Yadav K, Narayana Murthy MR, Kavitha HS. Patient based factors influencing drug compliance among hypertensive patients in a tertiary care hospital in Mysore. Int J Res Med Sci. 2015 Jun;3(6):1435-8.

19. Mitchell WG, Scheier LM, Baker SA. Adherence to treatment in children with epilepsy: who follows "doctor's orders"? Epilepsia. 2000 Dec;41(12):161625.

20. Mohammed S, Arabi A, E-Menyar A, Abdulkarim S, AlJundi A, Alqahtani A, et al. Impact of Polypharmacy on Adherence to Evidence-Based Medication in Patients who Underwent Percutaneous Coronary Intervention. Curr Vasc Pharmacol. 2016;14(4):388-93.

Cite this article as: Mir SA, Muzamil F, Bhat MUD, Amin A, Shakeel D. Assessment of medication adherence among patients with chronic diseases: a descriptive cross-sectional study. Int J Basic Clin Pharmacol 2019;8:115-9. 